\title{
ALTERAÇÕES INCIDENTAIS DOS SEIOS DA FACE NA TOMOGRAFIA COMPUTADORIZADA DO CRÂNIO E ÓRBITAS EM CRIANC̣AS*
}

\author{
Severino Aires de Araújo Neto ${ }^{1}$, Antônio Soares Souza ${ }^{2}$, Inês Minniti Rodrigues Pereira ${ }^{3}$, \\ Emílio Carlos Elias Baracat ${ }^{4}$
}

Resumo OBJETIVO: Avaliar a prevalência e as características das alterações tomográficas incidentais dos seios da face em crianças sem quadro clínico de rinossinusite. MATERIAIS E MÉTODOS: Foram estudados pacientes entre zero e 18 anos de idade, submetidos a tomografia computadorizada do crânio ou órbitas por indicações não relacionadas a doença sinusal. RESULTADOS: Foram incluídas 64 crianças (idade média $=5,7$ anos; desvio-padrão = 3,9). Achados incidentais nos seios da face ocorreram em 46 casos (72\%). Na maioria $(25 / 46)$ as alterações eram discretas e o espessamento mucoso foi o achado incidental mais comum. Opacificação completa ou nível líquido foram observados em 12 crianças. Mais de um seio foi afetado em 33 pacientes, ocorrendo com maior freqüência nos seios maxilares, seguidos dos etmoidais. 0 acometimento bilateral e simétrico foi comum. As anormalidades ocorreram com maior prevalência, intensidade e extensão em crianças abaixo de três anos de idade. CONCLUSÃO: A prevalência de alterações tomográficas incidentais em crianças sem quadro clínico de rinossinusite é alta, predominando as definidas como discretas. A alteração mais encontrada é o espessamento mucoso. Achados incidentais moderados e acentuados tendem a ocorrer em crianças com menos de três anos de idade.

Unitermos: Tomografia computadorizada; Rinossinusite; Achados incidentais; Seios paranasais; Seios da face; Radiologia; Pediatria.

Abstract Incidental paranasal sinuses abnormalities in pediatric patients using computed tomography of the head and orbits.

OBJECTIVE: To evaluate the prevalence and appearance of incidental paranasal sinuses abnormalities in children with no clinical evidence of rhinosinusitis using CT scans. MATERIALS AND METHODS: CT scans of the head or orbits of children between 0 and 18 years of age performed due to problems not related to rhinosinusitis were studied. RESULTS: Sixty-four children were included (mean age 5.7 years; standard deviation $=3.9$ ). Incidental sinuses abnormalities were found in 46 cases $(72 \%)$. In most cases the abnormalities were mild (25/46) and mucosal thickening was the most common finding. Complete opacification and fluid levels occurred in 12 children. More than one cavity was affected in $\mathbf{3 3}$ patients and abnormalities were most frequently seen in maxillary sinuses, followed by ethmoid sinuses. Bilateral and symmetric findings were common. The prevalence and intensity of abnormalities were higher in children below three years of age. CONCLUSION: Incidental abnormalities are highly prevalent and tend to be mild in children without symptoms of rhinosinusitis. The most prevalent abnormality was mucosal thickening. Moderate and severe abnormalities occur in children below three years of age.

Key words: Computed tomographic scans; Rhinosinusitis; Incidental abnormalities; Paranasal sinuses; Radiology; Pediatrics.

\footnotetext{
* Trabalho realizado na Faculdade de Ciências Médicas da Universidade Estadual de Campinas (FCM-Unicamp), Campinas, $\mathrm{SP}$, e na Faculdade de Medicina de São José do Rio Preto ( $\mathrm{Fa}$ merp), São José do Rio Preto, SP.

1. Radiologista do Centro de Assistência Integral à Saúde da Mulher (CAISM)-Unicamp e da Tomovale - São José dos Campos, Mestre em Saúde da Criança e do Adolescente pela FCMUnicamp.

2. Professor Assistente Doutor, Chefe do Serviço de Radiologia do Hospital de Base de São José do Rio Preto - Famerp.

3. Professora Assistente Doutora, Chefe do Departamento de Radiologia da FCM-Unicamp.

4. Professor Assistente Doutor do Departamento de Pediatria da FCM-Unicamp.

Endereço para correspondência: Dr. Severino Aires de Araújo Neto. Rua Hermantino Coelho, 195, ap. 113, Plaza. Campinas, SP, 13087-500. E-mail: severinoaires@hotmail.com

Recebido para publicação em 15/9/2004. Aceito, após revisão, em 9/12/2004.
}

\section{INTRODUÇÃO}

Na população pediátrica, uma das indicações mais freqüentes de antibioticoterapia é a rinossinusite aguda, também responsável por grande volume de absenteísmo escolar ${ }^{(1,2)}$

Vários fatores dificultam o diagnóstico clínico da rinossinusite bacteriana em crianças, principalmente devido ao quadro sintomático sobreposto e de difícil distinção dos processos alérgicos e virais ${ }^{(\mathbf{1 , 2})}$. Adicionalmente, os dados de exame físico são escassos, pois os seios da face não podem ser examinados diretamente, im- pondo desafios a um diagnóstico seguro e conseqüente emprego adequado de antibióticos, principalmente em crianças com quadros clínicos indefinidos ${ }^{(3)}$.

Os exames de diagnóstico por imagem, particularmente a tomografia computadorizada (TC), mostram boa correlação entre a presença de alterações e o diagnóstico clínico de rinossinusite aguda e crôni$\mathrm{ca}^{(3-5)}$. Nos quadros recorrentes e crônicos, a prevalência dessas alterações tomográficas, desde espessamento mucoso até opacificação completa, é elevada, variando de $63 \%$ a $100 \%$, dependendo da metodologia do estudo ${ }^{(6-8)}$. 
Quando comparadas à TC na identificação de opacidades sinusais em crianças, as radiografias simples apresentam valores falso-positivos de até $36 \%{ }^{(6,9)}$. Por outro lado, outros estudos demonstram também baixa sensibilidade na detecção da doença sinusal. Garcia et al. ${ }^{(\mathbf{8})}$ observaram que as radiografias falham em detectar anormalidades sinusais em $25 \%$ dos pacientes com quadro clínico de rinossinusite crônica e opacificação à tomografia, portanto, sem um valor preciso e definido no diagnóstico da doença em crianças.

A TC oferece boa resolução espacial e elimina a superposição de estruturas pela confecção de imagens seccionais, permitindo, assim, avaliar adequadamente a anatomia da região da face e suas freqüentes variações. Nas últimas duas décadas, com o advento da cirurgia endoscópica funcional dos seios da face e com a importância conferida ao papel da disfunção do complexo óstio-meatal na fisiopatogenia da rinossinusite crônica, o detalhamento anatômico da TC tornou-se fundamental no estudo dos seios da face ${ }^{(\mathbf{1 0 )}}$. Para o diagnóstico da rinossinusite aguda não complicada, a TC não é necessária. Mas ela assume papel bem definido nos casos agudos refratários à terapia clínica, na suspeita de complicações, nos casos crônicos ou recorrentes (principalmente naqueles em que se planeja intervenção cirúrgica) e nas avaliações pós-operatórias ${ }^{(\mathbf{1 1}, 12)}$. Entretanto, no que diz respeito à especificidade no diagnóstico da rinossinusite infecciosa, a TC ainda é deficiente, já que as alterações inflamatórias geradas por processos alérgicos ou virais são muitas vezes indistinguíveis das alterações bacterianas ${ }^{(\mathbf{1 , 4}, \mathbf{1 3})}$.

Além disso, podem ser encontradas alterações significativas dos seios da face à tomografia de indivíduos sem qualquer sintoma de rinossinusite. Essas alterações, denominadas achados incidentais, são comuns, mas seu significado e sua importância no desencadeamento ou não do processo infeccioso em seios da face ainda estão indefinidos ${ }^{(14-16)}$. Devido à alta freqüência em que são encontrados em crianças ${ }^{(\mathbf{1 7}, 18)}$, podem ser incorretamente relacionados a situações clínicas, gerando erros diagnósticos. Assim, o conhecimento da prevalência e a caracterização desses achados em populações assintomáticas podem ajudar a definir o seu significado, traçar limites de normalidade e critérios de diagnósticos mais confiáveis. Conhecendo esses dados de normalidade e doença, o profissional médico adotaria condutas com mais segurança, frente a crianças assintomáticas ou com quadros clínicos limítrofes e que apresentam alterações sinusais nos exames radiológicos.

O objetivo deste trabalho foi determinar a prevalência de alterações tomográficas incidentais dos seios da face em crianças sem quadro clínico de rinossinusite, caracterizando a intensidade, a distribuição anatômica e os tipos predominantes dessas alterações.

\section{MATERIAIS E MÉTODOS}

O desenho do estudo é do tipo transversal de prevalência.

Foram incluídos pacientes entre zero e 18 anos de idade, que realizaram TC da órbita ou do crânio, solicitadas por motivos diversos não relacionados à rinossinusite.

Os critérios de exclusão foram: quadro clínico de rinossinusite referido no pedido do exame, diagnóstico pregresso de rinossinusite há menos de dois meses ou mais de três episódios diagnosticados nos últimos 12 meses, exame de TC motivado por trauma craniano, precedente de radioterapia na região do crânio e fibrose cística.

Um questionário foi aplicado aos pais para verificar sinais e sintomas relacionados ao trato respiratório superior ${ }^{(19)}$. A partir deste, obtinha-se uma pontuação (escore S5) que podia variar de zero a três, de acordo com a intensidade das manifestações clínicas. Foram considerados sintomáticos e também excluídos da casuística os pacientes que obtivessem pontuação de escore S5 maior que um, independente da duração dos sintomas. Para os pacientes incluídos foi obtido termo de consentimento informado dos pais ou responsáveis.

No exame de TC de crânio foram adicionados dois cortes tomográficos extras, mais caudais, com a mesma espessura dos cortes para a fossa posterior do crânio, no nível dos seios maxilares (Figuras 1 e 2), angulados de forma a não cruzarem o plano do cristalino. No exame de órbitas, não houve acréscimo de nenhum corte, pois as imagens revelavam bem os seios da face.
Os exames foram realizados no Serviço de Radiologia do Hospital de Base de São José do Rio Preto, entre maio de 2001 e agosto de 2002, e no Departamento de Radiologia do Hospital das Clínicas da Universidade Estadual de Campinas (Unicamp), entre abril e outubro de 2003.

Foram utilizados três aparelhos de TC: Tomoscan SR-4000 (Philips), Helicat Flash (Elscint) e Somaton AR (Siemens), ajustados a 100-130 kV e 150-210 mAs. Os cortes tomográficos foram registrados em películas com janelas para osso (nível de 200 a 500, largura de 1.500 a 2.500) e/ou numa janela intermediária (nível de zero e largura de 1.000 a 2.000), ambas adequadas para avaliação de cavidades aeradas.

Os exames foram interpretados independentemente por dois radiologistas, que pesquisaram: a) desenvolvimento (presença) de cada seio; b) grau de opacificação de cada seio; c) achados específicos, como opacificação completa, nível líquido e pólipos ou cistos nos seios da face. As discordâncias eram resolvidas por um terceiro radiologista, que em cada um dos itens optava por uma ou outra das interpretações anteriores. Os radiologistas não tiveram acesso ao quadro clínico do paciente. Os seios foram considerados pares (um de cada lado), excetuando-se o esfenóide, tido como cavidade única.

Com o intuito de quantificar a opacificação dos seios da face, foi elaborado um sistema de escore denominado "razão opacificação/desenvolvimento" (ROD). A ROD consistiu numa estimativa da proporção da área de seios da face desenvolvidos que está tomada por opacificação, a saber:

- Desenvolvimento dos seios da face ("D"): pontuação de quatro para cada seio desenvolvido e zero para os não desenvolvidos. A pontuação final ("D”) resultou da soma dos pontos de todas as sete cavidades paranasais (seios maxilares, etmoidais e frontais em pares mais o seio esfenoidal), variando de zero a 28.

- Opacificação dos seios da face (“O”): pontuação da opacificação de cada seio em: 0 (zero): normal; 1 (um): < 1/3 da área do seio opacificada; 2 (dois): $1 / 3$ a $2 / 3$ da área do seio opacificada; 3 (três): > 2/3 do seio opacificada; 4 (quatro): opacificação total do seio. Os seios não desenvolvidos receberam zero nessa coluna. A pontuação 


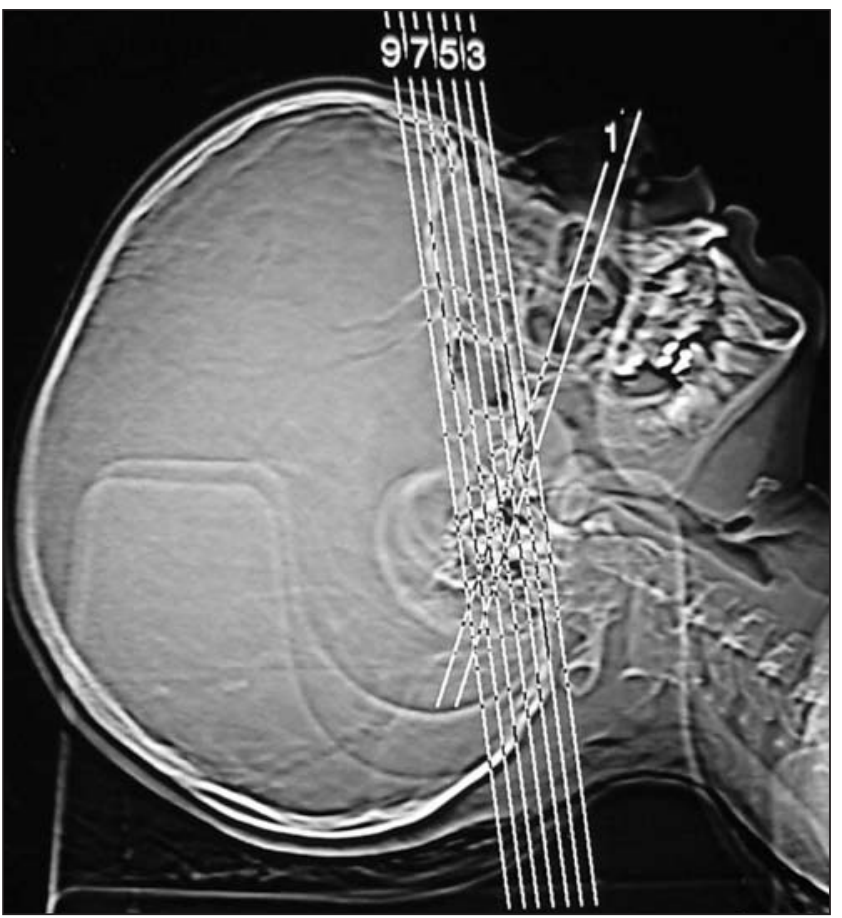

Figura 1. Escanograma com planos tomográficos do exame do crânio. As duas linhas mais inferiores correspondem aos dois tomogramas adicionados ao protocolo padrão para a visualização dos seios maxilares. As linhas restantes representam os cortes tomográficos da fossa posterior do crânio.

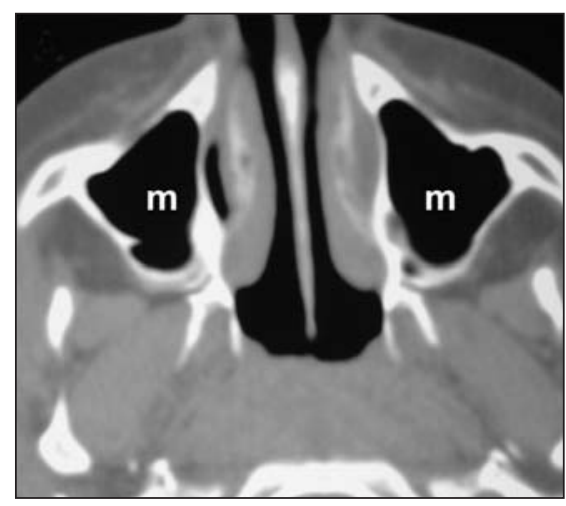

A

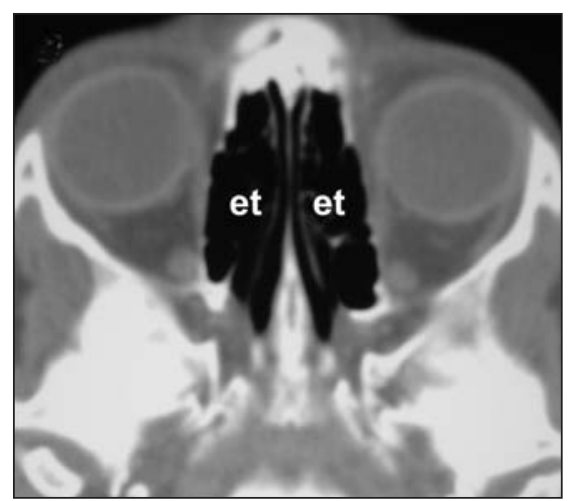

C

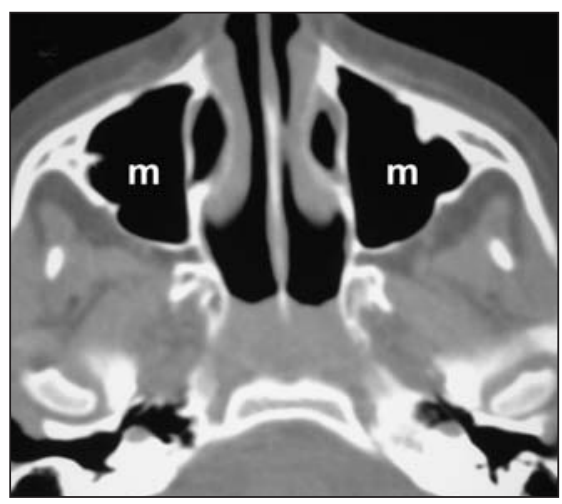

B

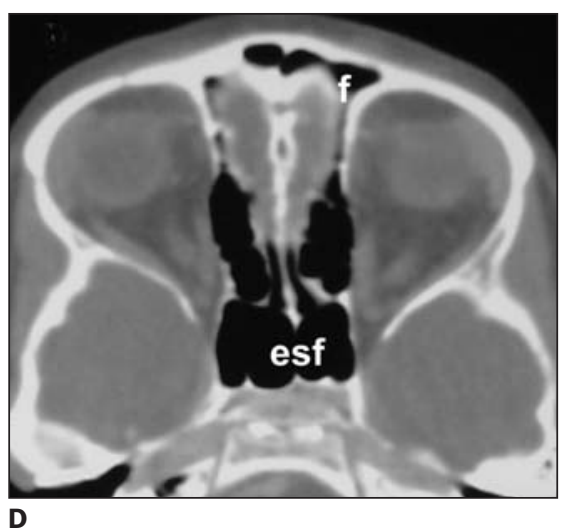

D

Figura 2. Cortes do exame de tomografia computadorizada de crânio nos vários níveis dos seios da face. Os dois primeiros (A e B) são cortes adicionados ao protocolo de crânio e demonstram os maxilares $(\mathrm{m})$; os cortes $\mathbf{C}$ e D fazem parte do protocolo padrão do exame do crânio e incluem os seios etmoidais (et), frontais (f) e esfenoidal (esf) final ("O”) foi obtida da soma dos pontos de opacificação de todos os seios da face, variando de zero a 28 .

O cálculo da ROD consistiu na razão "O”/“D”, oferecendo uma estimativa da porcentagem de área total dos seios da face desenvolvidos que se encontrava opacificada. Quatro níveis de intensidade de opacificação tomográfica foram definidos, segundo o valor da ROD:

a) ROD = 0: exame tomográfico normal;

b) ROD < 30: opacificação discreta;

c) $\mathrm{ROD} \geq 30$ e < 60: opacificação moderada;

d) ROD $\geq 60$ : opacificação acentuada.

O termo de consentimento e o protocolo de pesquisa foram previamente aprovados pelos Comitês de Ética em Pesquisa da Faculdade de Ciências Médicas da Unicamp e da Faculdade de Medicina de São José do Rio Preto.

A análise estatística para verificar relação entre variáveis consistiu na aplicação de teste não paramétrico de Mann-Whitney (para variáveis contínuas), testes quiquadrado, exato de Fisher e McNemar (para variáveis categóricas). Para comparar os valores de ROD entre grupos usaram-se testes não-paramétricos de MannWhitney e Kruskal-Wallis e também o teste de comparação de médias de Tukey. Para verificar tendência de agrupamento de opacificação do mesmo lado aplicou-se o teste não paramétrico de Wilcoxon e teste de simetria. Foi utilizado nível de significância estatística de 5\% (p-valor < 0,05).

\section{RESULTADOS}

Foram incluídos no estudo 64 pacientes com idade variando entre 0,4 e 15 anos ( média $=5,7$; desvio-padrão $=3,9$ ), sendo 34 do sexo masculino $(53,12 \%)$. Dos 64 pacientes, seis tinham menos de um ano de idade $(9,38 \%), 12$ tinham entre um e dois anos $(18,75 \%)$ e os demais 46 tinham três anos ou mais $(71,87 \%)$.

Dos exames de TC, apenas um foi de órbita, sendo o restante de crânio $(98,43 \%)$. Os motivos mais freqüentes da investigação tomográfica foram: retardo do desenvolvimento neuropsicomotor $(17,19 \%)$, convulsão ou epilepsia $(10,94 \%)$, cefaléia $(9,38 \%)$, suspeita de tumores $(6,25 \%)$ ou má-formação do sistema nervoso central $(3,13 \%)$ e 
hipertensão intracraniana $(4,69 \%)$. Em $35,94 \%$ dos casos a indicação do exame não constava na guia de solicitação.

A pontuação do questionário de admissão (que podia variar de zero a um) mostrou média $=0,43$ (desvio-padrão $=0,32$ ).

$\mathrm{Na}$ avaliação tomográfica dos seios da face, os seios maxilares e etmoidais mostraram-se desenvolvidos (presentes) em todos os pacientes, o seio esfenoidal esteve presente em 35 pacientes $(55,5 \%)$ e os seios frontais, em $16 / 60$ pacientes $(26,7 \%)$, não sendo documentados pelas imagens em quatro casos com nove anos ou mais. A presença dos seios esfenoidal e frontais tendeu a aumentar com a idade, exceto por pequeno decréscimo no aparecimento dos frontais a partir de nove anos (Gráfico 1). A detecção da presença dos seios da face não diferiu entre os sexos.

A TC foi normal em 18 pacientes $(28,1 \%)$. Nos 46 restantes $(71,9 \%)$, a TC mostrou achados incidentais que incluíam desde leve espessamento mucoso até velamento completo de um ou vários seios. A frequiência dos quatro níveis de intensidade da opacificação tomográfica - normal $(\mathrm{ROD}=0)$, discretos (ROD < 30), moderados $(\mathrm{ROD} \geq 30$ e $<60)$ e acentuados (ROD $\geq 60)$ — é mostrada no Gráfico 2.

A Tabela 1 apresenta a freqüência dos níveis de opacificação de acordo com a faixa etária e demonstra que quanto mais novos os pacientes, maior foi a tendência de apresentarem opacificação moderada e acentuada $(\mathrm{p}=0,012)$, a ponto de nenhum paciente menor de um ano apresentar resultado normal.

A Tabela 2 dispõe as médias e as variações dos valores da ROD nas três faixas etárias, com diferenças significativas entre elas ( $p=0,003)$, sendo a maior média encontrada nos pacientes menores de um ano, seguidos pelos entre um e dois anos.

Não houve diferença significativa de prevalência de achados tomográficos por sexo, sendo que 24 dos 46 pacientes com seios alterados eram do sexo masculino $(52,2 \%)(\mathrm{p}=0,69)$.

Os seios da face mais freqüentemente acometidos foram os maxilares, com 38 pacientes $(59,4 \%)$, e os etmoidais, com 28 $(43,7 \%)$, em pelo menos um lado. Dos 26 pacientes com seio esfenoidal desenvolvido, nove apresentavam alterações $(25,7 \%)$.

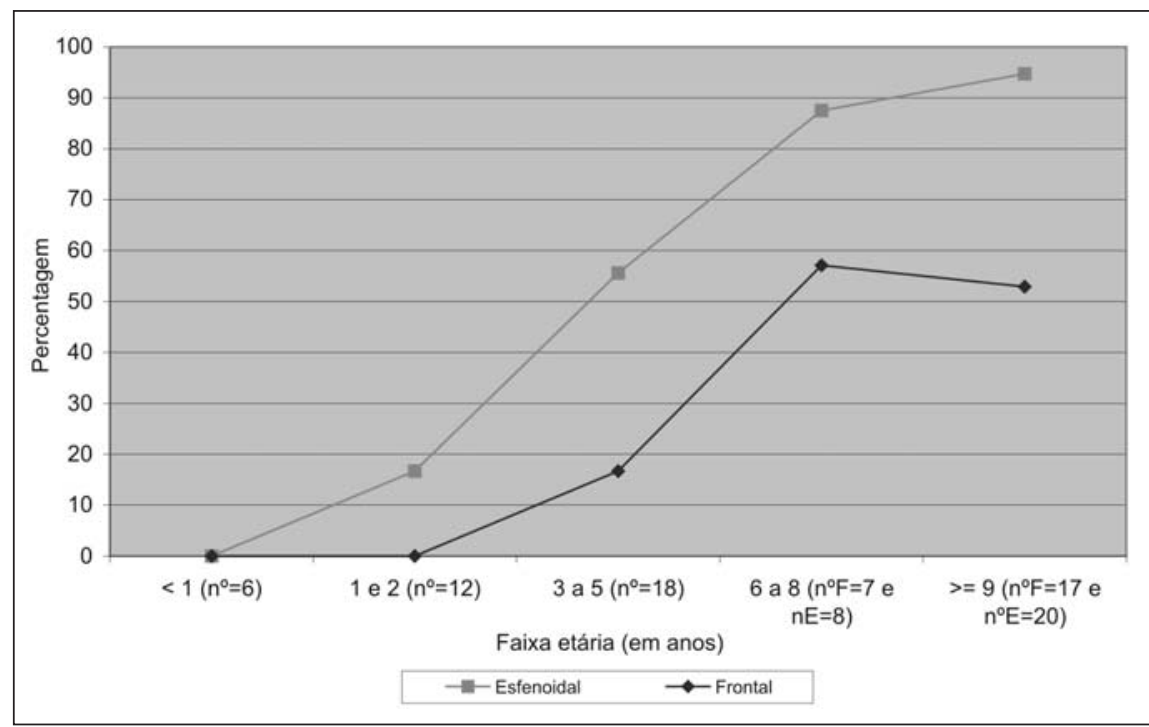

Gráfico 1. Desenvolvimento dos seios da face segundo a faixa etária (\%). ( ${ }^{\circ} \mathrm{F}$, número de seios frontais documentados; nE, número de seios esfenoidais documentados).

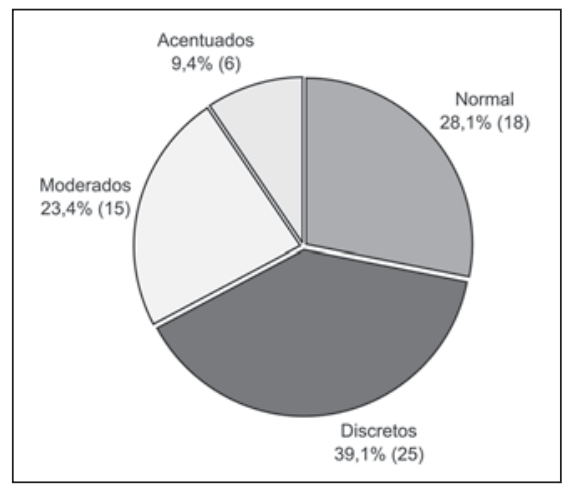

Gráfico 2. Freqüência de níveis de opacificação tomográfica dos seios da face (números absolutos entre parênteses).
Apenas um dentre os 16 seios frontais desenvolvidos apresentou alterações à TC.

Não foi observada preferência significativa de acometimento por qualquer dos lados (teste de simetria: $\mathrm{p}=0,19$ ).

Dos 46 pacientes com alterações tomográficas, $13(28,3 \%)$ apresentaram apenas um seio da face alterado, $10 \mathrm{com}$ dois seios acometidos $(21,7 \%)$ e os restantes $23 \mathrm{com}$ três ou mais $(50,0 \%)$. Nas 33 crianças com mais de um seio alterado, 26 (78,8\%) apresentaram alterações simétricas e homólogas, e sete $(21,2 \%)$, mais seios acometidos de um lado do que de outro (Tabela 3).
Tabela 1 Freqüência de níveis de opacificação tomográfica segundo a faixa etária.

\begin{tabular}{|c|c|c|c|c|c|c|}
\hline & & Normal & Discretos & Moderados & Acentuados & Total \\
\hline \multirow{3}{*}{$\begin{array}{l}\text { Faixa } \\
\text { etária }\end{array}$} & $<1$ ano & $\begin{array}{l}0 \\
(0 \%)\end{array}$ & $\begin{array}{l}1 \\
(16,7 \%)\end{array}$ & $\begin{array}{l}4 \\
(66,6 \%)\end{array}$ & $\begin{array}{l}1 \\
(16,7 \%)\end{array}$ & 6 \\
\hline & 1 a 2 anos & $\begin{array}{l}2 \\
(16,7 \%)\end{array}$ & $\begin{array}{l}3 \\
(25,0 \%)\end{array}$ & $\begin{array}{l}5 \\
(41,6 \%)\end{array}$ & $\begin{array}{l}2 \\
(16,7 \%)\end{array}$ & 12 \\
\hline & $\geq 3$ anos & $\begin{array}{l}16 \\
(34,8 \%)\end{array}$ & $\begin{array}{l}21 \\
(45,7 \%)\end{array}$ & $\begin{array}{l}6 \\
(13,0 \%)\end{array}$ & $\begin{array}{l}3 \\
(6,5 \%)\end{array}$ & 46 \\
\hline \multicolumn{2}{|r|}{ Total } & $\begin{array}{l}18 \\
(28,1 \%)\end{array}$ & $\begin{array}{l}25 \\
(39,1 \%)\end{array}$ & $\begin{array}{l}15 \\
(23,4 \%)\end{array}$ & $\begin{array}{l}6 \\
(9,4 \%)\end{array}$ & $\begin{array}{l}64 \\
(100 \%)\end{array}$ \\
\hline
\end{tabular}

Teste exato de Fisher: $p=0,012$.

Tabela 2 Distribuição da amostra razão opacificação/desenvolvimento segundo a faixa etária.

\begin{tabular}{|l|l|c|c|r|}
\hline & Média* & Desvio-padrão & Variação \\
\hline \multirow{3}{*}{ Faixa etária } & $<1$ ano & 46,67 & 25,22 & $12-87$ \\
& 1 a 2 anos & 33,25 & 29,38 & $0-87$ \\
& $\geq 3$ anos & 15,24 & 21,16 & $0-90$ \\
\hline
\end{tabular}

$* p=0,003$ 
Tabela 3 Distribuição do acometimento sinusal entre os lados quando mais de um seio estava alterado.

\begin{tabular}{|l|l|c|c|}
\hline \multicolumn{2}{|l|}{ Acometimento } & Número & Porcentagem \\
\hline \multirow{2}{*}{ Simétrico } & Maxilar bilateral & 8 & $24,2 \%$ \\
$(26 ; 78,8 \%)$ & Etmoidal bilateral & 2 & $6,1 \%$ \\
& Maxilo-etmoidal bilateral & 16 & $48,5 \%$ \\
\hline Assimétrico & Dois seios de um lado e um do outro & 5 & $15,1 \%$ \\
$(7 ; 21,2 \%)$ & Dois seios de um lado e nenhum do outro & 2 & $6,1 \%$ \\
\hline \multicolumn{2}{|c|}{ Total } & 33 & $100,0 \%$ \\
\hline
\end{tabular}

Espessamento mucoso foi o tipo de achado mais comum e esteve presente em 42 dos 46 pacientes com alterações. A opacificação completa ocorreu em 11 pacientes $(23,9 \%)$, sendo oito menores de três anos, mostrando uma tendência dos velamentos ocorrerem em faixas etárias menores $(\mathrm{p}<0,001)$. Em apenas dois pacientes foi observado nível líquido $(4,3 \%)$, sendo um no grupo menor de um ano e outro no grupo maior ou igual a três anos. Em cinco pacientes apareceram cistos/pólipos, todos eles com três anos ou mais, sem atingir diferença significativa entre faixas etárias $(\mathrm{p}=0,31)$. Dois ou mais tipos de alterações apresentaram-se concomitantemente em 13 pacientes; em oito consistia de associação de espessamento mucoso com opacificação completa.

Dos 12 pacientes com velamento e/ou nível líquido, a ROD foi moderada a acentuada em 11 deles, mostrando que houve forte correlação positiva entre a presença desses achados, considerados mais específicos de rinossinusite, com a maior intensidade de opacificação medida pela ROD.

\section{DISCUSSÃO}

No diagnóstico da rinossinusite, os exames por imagem não são necessários para confirmar o diagnóstico clínico, principalmente nos quadros não complicados em crianças menores de seis anos ${ }^{(\mathbf{1 , 1 2})}$.

A TC, apesar de apresentar alta sensibilidade na detecção de anormalidades dos seios da face, é proposta apenas nos casos complicados, crônicos e recorrentes. O encontro de alterações incidentais em indivíduos normais reforça o papel seletivo desse exame.

A prevalência de achados incidentais em seios da face no presente estudo, mais de dois terços da amostra $(71,9 \%)$, superou significativamente o que é descrito na literatura. Em pacientes adultos assintomáticos, Fascenelli ${ }^{\mathbf{( 2 0 )}}$ demonstrou alterações em um terço das radiografias simples. Mais de crânio, encontraram cerca de $42 \%$ de alterações $^{(3)}$. Avaliando exames de TC ou ressonância magnética do crânio, órbitas ou osso temporal em crianças sem sintomas son et al..$^{(\mathbf{1 5})}$ e Manning et al. ${ }^{(\mathbf{1 6})}$ detectaram alterações em $41 \%$ a $47 \%$ do total de pacientes estudados.

Considerando que o estudo foi realizado em crianças, optou-se pela elaboração de um escore de TC (ROD) que levasse em conta o tamanho da opacificação do seio da face, frente à área total desenvolvida, criando-se uma proporção entre as duas, independentemente de quantos e quais seios estivessem presentes. Esta metodologia fez-se necessária diante do fato de que apenas os seios maxilares e etmoidais costumam aparecer em TC de neonatos, enquanto os seios etmoidais e frontais podem estar normalmente ausentes em crianças com mais de nove anos de idade. A diferença verificada na prevalência de opacificação incidental neste estudo e nos demais pode ser explicada em parte pelo fato de que a avaliação da TC aqui adotada levou em consideração espessamentos mucosos menores que $3 \mathrm{~mm}$, como recomendado por Som ${ }^{(\mathbf{2 1})}$. Além disso, a documentação da TC numa janela intermediária ou em janela para osso, mais apropriadas para análise de cavidades dos seios da face, pode ter aumentado a sensibilidade do exame e, conseqüentemente, a prevalência dos achados. Já o fato de terem sido incluídos pacientes menores de um ano - nos quais a prevalência de achados incidentais recentemente, Havas et al., estudando TC de rinossinusite, Diament et al. ${ }^{(\mathbf{1 4})}$, Lesser- é sabidamente maior — não parece ser isoladamente uma forte justificativa para este número, posto que mesmo excluindo todos os pacientes menores que três anos, a prevalência medida (63\%) ainda é mais alta em relação a dados já referidos em populações assintomáticas.

Em relação à intensidade dos achados tomográficos incidentais (discreto, moderado e acentuado), observou-se predomínio de alterações semelhantes àquelas descritas na literatura para pacientes não sinusopatas, ou seja, prevaleceram as opacificações discretas (ROD < 30). Opacificação total de um seio (velamento) e o nível hidroaéreo, sinais mais específicos da rinossinusite bacteriana ${ }^{(4)}$, ocorreram em poucos pacientes, 11 e dois, respectivamente. Lesserson et al. ${ }^{(\mathbf{1 5})}$ evidenciaram espessamento mucoso importante ou velamento em apenas 14 de 142 TC (10\%) de crianças sem sintomas de rinossinusite. Em pacientes com quadros respiratórios de tosse, asma ou rinite, mas sem rinossinusite aguda, estudados por De Cleyn et al. ${ }^{(22)}$, $54 \%$ apresentaram alterações tomográficas sinusais e na maioria o espessamento mucoso era o único achado.

O parâmetro idade pareceu exercer influência também sobre a intensidade e extensão dos achados incidentais. As alterações moderadas e acentuadas (os maiores valores da ROD) prevaleceram em crianças menores de três anos, o que pode ser explicado pelas menores dimensões dos seios da face nessa fase da vida ${ }^{(23)}$. Ainda segundo alguns autores, o achado de opacidades no interior dos seios da face em pacientes abaixo de um ano de idade é completamente normal; faz parte do processo de desenvolvimento do seio, podendo representar fluido ou medula vermelha, cuja conversão em medula amarela precede a pneumatização sinusal $^{(\mathbf{2 3 , 2 4})}$.

Em estudos com população adulta não sinusopata, os seios maxilares são os que mais apresentam alterações incidentais (28\%), seguidos das células etmoidais anteriores $(19 \%)^{(\mathbf{2 5})}$. Em crianças, os índices chegam a $39 \%$ para os maxilares, $31 \%$ para os etmoidais e $17 \%$ nos esfenoidais ${ }^{(15)}$. Na presente casuística, o seio maxilar foi o mais freqüentemente acometido, seguido do etmoidal e esfenoidal, corroborando esses relatos. 
As causas pelas quais alguns indivíduos sem rinossinusite apresentam espessamento mucoso ou até mesmo velamento e nível líquido nos seus seios da face em exames radiológicos não são conhecidas. Alterações nos exames por imagem podem ser causadas não só pela rinossinusite bacteriana, como até mesmo pelo ciclo fisiológico de aumento de volume da mucosa nasal, que ocorre alternadamente de um lado para outro ${ }^{(26)}$, ou mesmo qualquer outro fenômeno que leve à inflamação da mucosa, como asma, rinite, produtos químicos e infecções virais ${ }^{(\mathbf{1 , 2 2})}$.

O emprego de critérios mais rigorosos na interpretação de certos achados de imagem como indicativos de rinossinusite pode ajudar a elevar a especificidade das radiografias e da TC. Segundo Wald ${ }^{(4)}$, os critérios diagnósticos de rinossinusite devem limitar-se à opacificação total ou nível líquido em pelo menos um seio da face ou espessamento mucoso de pelo menos $4 \mathrm{~mm}$.

Os dois tomogramas adicionados ao protocolo de TC de crânio nos pacientes estudados foram essenciais para a avaliação dos seios maxilares, os mais afetados pelas alterações. Apesar de os sujeitos desta pesquisa terem realizado seus exames tomográficos por indicações clínicas pertinentes, não relacionadas à avaliação dos seios da face ou ao objetivo desse trabalho, cabe salientar que essa exposição não parece oferecer risco adicional significativo. Lanzieri $^{(27)}$ verificou que seu protocolo limitado para TC dos seios da face, composto de seis cortes axiais, implicava dose de radiação significativamente menor do que a oferecida pelas radiografias simples. Um estudo que usou voltagem e corrente semelhantes aos dos protocolos do presente estudo verificou que o fator determinante mais importante na dosagem da radiação para o cristalino é a quantidade de cortes na região das órbitas e não o número total de cortes. Foi verificado, então, que a dose total de radiação proporcionada pela técnica padrão de TC dos seios da face (cerca de 33 cortes em planos axial e coronal) foi, em média, cerca de 22 miligrays ( $m G y$ ). Esse valor é quase 100 vezes menor do que a dose crítica para o desenvolvimento de catarata $(2.000 \mathrm{mGy})^{(\mathbf{2 8})}$. Assim, dois cortes tomográficos adicionais implicam dose de 1,3 mGy. Além disso, os cortes foram angulados em planos que não incluíssem as órbitas, de forma a reduzir ainda mais os efeitos dos raios $\mathrm{X}$ sobre o cristalino.

Com base nos achados deste estudo, pode-se concluir que a prevalência de alterações tomográficas incidentais em crianças sem quadro clínico de rinossinusite foi alta, predominando as definidas como discretas. De acordo com a faixa etária, quanto mais novos os pacientes, maior foi a tendência de apresentarem achados incidentais moderados e acentuados.

Os seios da face mais freqüentemente acometidos foram os maxilares, seguidos dos etmoidais. Nos pacientes com alterações tomográficas, a maioria apresentou mais de um seio da face acometido, predominando a simetria entre os lados. A alteração mais encontrada foi o espessamento mucoso, seguido do velamento. Este último tendeu a ocorrer em faixas etárias menores.

\section{REFERÊNCIAS}

1. American Academy of Pediatrics. Subcommittee on Management of Sinusitis and Committee on Quality Improvement. Clinical practice guideline: management of sinusitis. Pediatrics 2001;108:798808.

2. Sociedad Espanõla de Quimioterapía y Sociedad Espanõla de Otorrinolaringolgía y Patología Cérvico-facial. (Consenso) Diagnóstico y tratamiento antimicrobiano de las sinusitis. Rev Esp Quimioterap 2003;16:239-51.

3. Havas TE, Motbey JA, Gullane PJ. Prevalence of incidental abnormalities on computed tomographic scans of the paranasal sinuses. Arch Otolaryngol Head Neck Surg 1988;114:856-9.

4. Wald ER. Radiographic sinusitis: illusion or delusion? Pediatr Infect Dis J 1993;12:792-3.

5. Lindbaek M, Johnsen UL, Kaastad E, et al. CT findings in general practice patients with suspected acute sinusitis. Acta Radiol 1996;37:708-13.

6. McAlister WH, Lusk R, Muntz HR. Comparison of plain radiographs and coronal CT scans in infants and children with recurrent sinusitis. AJR 1989; 153:1259-64.

7. April MM, Zinreich SJ, Baroody FM, Naclerio RM. Coronal CT scan abnormalities in children with chronic sinusitis. Laryngoscope 1993;103:985-90.

8. Garcia DP, Corbett ML, Eberly SM, et al. Radiographic imaging studies in pediatric chronic sinusitis. J Allergy Clin Immunol 1994;94(3 Pt 1):52330 .

9. Lazar RH, Younis RT, Parvey LS. Comparison of plain radiographs, coronal $\mathrm{CT}$, and intraoperative findings in children with chronic sinusitis. Otolaryngol Head Neck Surg 1992;107:29-34.

10. Zinreich SJ, Kennedy DW, Rosenbaum AE, Gayler BW, Kumar AJ, Stammberger H. Paranasal sinuses: CT imaging requirements for endoscopic surgery. Radiology 1987;163:769-75.
11. Diament MJ. The diagnosis of sinusitis in infants and children: x-ray, computed tomography, and magnetic resonance imaging. Diagnostic imaging of pediatric sinusitis. J Allergy Clin Immunol 1992;90(3 Pt 2):442-4.

12. McAlister WH, Parker BR, Kushner DC, et al. Sinusitis in the pediatric population. In: ACR Appropriateness criteria. Reston: American College of Radiology, 2000. Available at: http://www.acr.org/ departments/appropriatness_criteria. Acessado em $22 / 1 / 2004$

13. Gwaltney JM Jr, Phillips CD, Miller RD, Riker DK. Computed tomographic study of the common cold. N Engl J Med 1994;330:25-30.

14. Diament MJ, Senac MO Jr, Gilsanz V, Baker S, Gillespie T, Larsson S. Prevalence of incidental paranasal sinus opacification in pediatric patients: a CT study. J Comput Assist Tomogr 1987;11:42631 .

15. Lesserson JA, Kieserman SP, Finn DG. The radiographic incidence of chronic sinus disease in the pediatric population. Laryngoscope 1994;104:159 66.

16. Manning SC, Biavati MJ, Phillips DL. Correlation of clinical sinusitis signs and symptoms to imaging findings in pediatric patients. Int J Pediatr Otorhinolaryngol 1996;37:65-74

17. Glasier CM, Ascher DP, Williams KD. Incidental paranasal sinus abnormalities on CT of children: clinical correlation. AJNR 1986;7:861-4.

18. Glasier CM, Mallory GB Jr, Steele RW. Significance of opacification of the maxillary and ethmoid sinuses in infants. J Pediatr 1989;114:45-50.

19. Garbutt JM, Gellman EF, Littenberg B. The development and validation of an instrument to assess acute sinus disease in children. Qual Life Res 1999; 8:225-33.

20. Fascenelli FW. Maxillary sinus abnormalities: radiographic evidence in an asymptomatic population. Arch Otolaryngol 1969;90:190-3.

21. Som PM. CT of the paranasal sinuses. Neuroradiology 1985;27:189-201.

22. De Cleyn KM, Kersschot EA, De Clerk LS, et al. Paranasal sinus pathology in allergic and non-allergic respiratory tract diseases. Allergy 1986;41: 313-8.

23. Spaeth J, Krugelstein U, Schlondorff G. The paranasal sinuses in CT-imaging: development from birth to age 25. Int J Pediatr Otorhinolaryngol 1997;39:25-40.

24. Scuderi AJ, Harnsberger HR, Boyer RS. Pneumatization of the paranasal sinuses: normal features of importance to the accurate interpretation of CT scans and MR images. AJR 1993;160:1101-4.

25. Bolger WE, Butzin CA, Parsons DS. Paranasal sinus bony anatomic variations and mucosal abnormalities: CT analysis for endoscopic sinus surgery. Laryngoscope 1991;101(1 Pt 1):56-64.

26. Kennedy DW, Zinreich SJ, Kumar AJ, Rosenbaum AE, Johns ME. Physiologic mucosal changes within the nose and ethmoid sinus: imaging of the nasal cycle by MRI. Laryngoscope 1988;98:92833

27. Lanzieri CF. A cavidade sinonasal. In: Haaga JR, Lanzieri CF, eds. Tomografia computadorizada e ressonância magnética do corpo humano. $3^{\mathrm{a}} \mathrm{ed}$. Rio de Janeiro: Guanabara-Koogan, 1996:422-40.

28. Moulin G, Chagnaud C, Waultier S, et al. Radiation dose to the lenses in CT of the paranasal sinuses. Neuroradiology 1996;38 Suppl 1:S127-9. 